\title{
EL CASTILLO DE PENNA CADIELLA EN LA SIERRA DE BENICADELL ${ }^{1}$.
}

\author{
Vicente CARLOS NAVARro Oltra \\ E.O.I. de Valencia
}

Tras la toma de Valencia por Jaime I en 1238, el avance catalano-aragonés prosigue hacia el sur y en pocos años son ocupadas las ciudades de Cullera (1239), Alcira (1242), Játiva (1244), Denia (1244) y Biar (1245). En 1244, tal vez 1245, el infante Alfonso, hijo de Jaime I, firma el tratado de El Pouet con un personaje llamado Abū 'Abd Allāh Muhammad b. Hudayl, más conocido por al-Azraq ${ }^{2}$. Con este tratado, al-Azraq conservaría durante tres años una serie de castillos situados en la zona montañosa entre Denia y Alcoy, al norte de la actual provincia de Alicante, y después debería entregarlos a Jaime I. Coincidiendo con el final de este plazo, al-Azraq encabezó una revuelta armada en la citada zona, durante la cual le arrebató varios castillos al rey aragonés ${ }^{3}$. Uno de los episodios más destacados de esta guerra fue el ataque de al-Azraq al castillo de Penacadell.

El único texto en el que se menciona con algún detalle el episodio de este asedio es el Llibre dels Feits, también conocido como la Crònica de Jaime I. En los capítulos 370 y 371 se describe la situa-

\footnotetext{
1 Algunas son las deudas de gratitud que este trabajo tiene contraídas con Carmen Barceló de la Universidad de Valencia, también con Salvador Climent Mañó y con los profesores Rosalía A. Benlloch, Antonio Martínez López, Cristian Porcar Bataller, Isaïes Minetto, Alexis Moya Benito y J. A. Gisbert.

2 Sobre este pacto y su fecha de redacción, véase Barceló, C., "Documentos árabes de al-Azrāq (1245-1250)", Saitabi 32 (1982), 27-41; Guichard, P., Les musulmans de Valence et la reconquête (XI'-XIII siècles), Damasco, 1991, II, 421-422 y documentos 68 a y 68 b; Burns, R. I. y Chevedden, P. E., Negotiating Cultures. Bilingual Surrender Treaties in Muslim-Crusader Spain, Leiden-Boston-Köln, 1999, 3-59 y bibliografia citada en este estudio.

${ }^{3}$ Para un resumen de esta sublevación y bibliografia sobre el tema, véase Guichard, P., Les musulmans, 421-433; López Elum, P., La conquista y repoblación valenciana durante el reinado de Jaime I, Valencia 1995, 219-226.
}

Al-Qanțara XXIII, 2 (2002) 299-329 
ción previa a la intervención de las tropas de Jaime I llegadas para levantar el asedio, así como su lucha contra los hombres de al-Azraq que hostigaban el castillo desde dos montes cercanos y la posterior retirada de éstos tras su fallido intento por apoderarse de él ${ }^{4}$.

Varios son los estudiosos que desde finales del siglo XIX han tratado de localizar este castillo y, a pesar de que, Guichard demostró, en un trabajo publicado en $1976^{5}$, que la fortaleza pudo asentarse en $E l$ Pic del Benicadell, el punto más alto de la sierra del mismo nombre, su situación exacta continúa siendo hasta hoy objeto de debate ${ }^{6}$. En lo que sí parecen estar de acuerdo todos los investigadores que se han ocupado del tema, ya sea desde el punto de vista histórico, ya sea desde el etimológico, es que este castillo de Penacadell es el de Peña o Penna Cadiella que se menciona en el Poema de Mio Cid.

El presente trabajo tiene como objetivo tratar de ubicar el castillo, aportando para ello nuevos datos documentales y arqueológicos.

\section{Las fuentes documentales}

\subsection{Fuentes árabes}

En la obra del geógrafo al-Idrīsī (1100-1164-5) titulada Uns al-muhay ${ }^{7}$ creo que se menciona este castillo. En la edición facsímil de los dos manuscritos que de esta obra he manejado, escritos con letra oriental, el topónimo aparece de dos formas distintas, y a mi pare-

\footnotetext{
${ }^{4}$ Varias son las fechas que se dan para dicho asedio que P. Guichard sitúa en 1258, vid. "Un toponyme historique de l'ancienne küra de Tudmïr", Murgetana, 45 (1976) 37-38; V. Subirats i Mulet cree que tuvo lugar en el año 1254, vid. "El Benicadell vist des d'Orta", Alberri, 6 (1993), 82, nota 13; J. Torró cree que hay que situarlo entre mediados de 1248 y principios de 1250, vid. El naiximent d'una colònia. Dominació $i$ resistència a la frontera valenciana (1238-1276), Valencia, 1999, 62.

5 Vid. supra, nota 4.

${ }^{6} \mathrm{Su}$ situación exacta sigue siendo discutida por parte de algún investigador. Vid. Torró, J., "Fortificaciones en Yibāl Balansiya. Una propuesta de secuencia", Castillos y territorio en al-Andalus, Granada 1998, 400, nota 23; Sala Giner, D., "El Cid en Penya Cadiella", Real Academia de Cultura Valenciana, Serie Histórica, 21 (2000), 129-145.

7 Al-Idrīìi, Uns al-muhay wa-rawḍ al-furây, reproducción facsímil de dos manuscritos preparada por Fuat Sezgin, Frankfurt, 1984; edición parcial, estudio y traducción de Jassim Abid Mizal, Los caminos de al-Andalus en el siglo XII, según "Uns al-muhaŷ wa rawd al-furaŷ" (Solaz de corazones y prados de contemplación), Madrid, 1989, texto ár. 67, trad. 94 y 305.
} 
cer ambas grafías son erróneas. Traduzco el fragmento en cuestión, que dice lo siguiente:

1. [Ms. í, fol. 159, línea 5] «... de Játiva al castillo (hisn) de n.bbah o b.nnah f.ṭal, que está sobre un río (calà nahr) hay 25 millas...»

2. [Ms. $\tau$, fol. 116, líneas 1 y 2] «... de Játiva al castillo (hișn) de $n . b a h$ w.tāl, que está sobre un río (calà nahr) hay 25 millas...»

A diferencia del manuscrito [ $\tau]$, en el manuscrito [i] las grafías de $t \bar{a}^{\prime}$ marbüta aparecen sin puntos diacríticos. En cuanto a la primera parte del topónimo, la $t \bar{a}$ ' marbūta, en ambos manuscritos, no tiene puntos diacríticos. Además, en esta primera parte del topónimo puede verse en el manuscrito [í] lo que creo que es el signo auxiliar šadda sobre la segunda consonante. A pesar de esto, creo que tanto $<$ n. bbah $>,<b . n n a h>, 0<n . b a h>$ deberían leerse $<$ binnah $>8$.

Respecto a la segunda parte del topónimo, es posible que ambas grafias sean incorrectas. En el caso de $\langle f . t a \bar{l}>$ el copista pudo incurrir en el error habitual, que es el de olvidar un punto diacrítico, en este caso en la primera letra, por lo cual habría que leer $<q . t \bar{a} l>9$. Respecto a la grafia $<w . t a \bar{l} l>$, el copista debió olvidar los puntos diacríticos además de confundir el apéndice de $f \bar{a}$ (ف) o $q \bar{a} f(\overrightarrow{0})$ con el trazo de $w \bar{a} w$ (و).

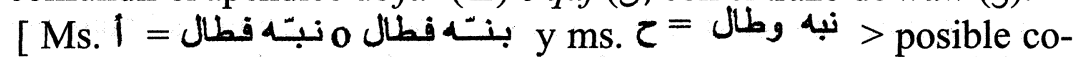

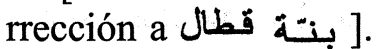

Por todo lo que acabamos de comentar, las posibles lecturas serían a mi juicio <binnah qatăl $>$, <binnah quțāl $>$ o <binnah qițāl $>$. A la vista de la forma del topónimo en las fuentes cristianas de la misma época creo que la lectura correcta podría ser <binnah qațāl $>10$.

\footnotetext{
${ }^{8}$ Lo que parece ser el término binna puede verse también en otra obra de al-Idrīsī, Nuzhat al-muštāq, Beirut 1989, II, 775, 777, nota 9, 778, 780, nota 11 (reimpresión en 2 vols. de la ed. E. Cerulli, F. Gabrielli, G. Della Vida y otros, Opus Geographicum, Nápoles 1970-1975 en 9 fascículos). Se trata de tres topónimos del sur de Italia de la región de Tarento que podrían hacer referencia a binna; hișn bin(n)a Anki, hișn bin(n)a D.bün.sī y hiș bin(n)a Tät.lì o Tüt.lì.

9 Este error de copista, habitual en todas las letras de igual trazo, que se diferencian únicamente por los puntos diacríticos, se repite en distintas ocasiones en los dos manuscritos de la obra de al-Idrīsî. A continuación señalo, a modo de ejemplo, tres casos en los que el copista de cada uno de los dos manuscritos citados parece confundir la letra $f \vec{a}$ (ف) con la $q a \bar{f}(\hat{}$ (ق); ms. fol. 144, línea 3, leemos hish al-q.šräl? en ms. ح, fol. 106, línea 18, hiș al-f.šäl?; ms. í, fol. 161, línea 1, leemos taraf al-l.w.fah? en ms. $\tau$, fol. 117, línea 3, taraf al-l.w.qah?; ms. í, fol. 162, línea 1, leemos marsà al-f.rūh? en ms. $\tau$, fol. 117, línea 17, marsà al-q.rüh?

${ }_{10}$ Al-Idrīsī, Uns al-muhay wa rawḍ al-furaŷ, ed. y trad. Jassim Abid Mizal, el cual interpreta este topónimo como Castillo de Peña Fatal, ibid., 305.
} 
Otro punto importante para la posible identificación de este topónimo con Benicadell es la distancia de 25 millas que, según al-Idrīsī, hay entre la ciudad de Játiva y este hișn, que además está sobre un río o cerca de él. En su estudio de la obra de al-Idrīsī, Mizal establece que una milla correspondería aproximadamente a una distancia de $1,2 \mathrm{~km}$. a $2,1 \mathrm{~km}{ }^{11}$. De hecho, entre el Benicadell y Játiva hay una distancia de 20 kilómetros en línea recta y por lo tanto la distancia que nos da al-Idrīsī de 25 millas correspondería a una distancia que iría de 30 a 52,5 kilómetros. Desde Játiva a Benicadell hay en torno a 35 kilómetros. Si el hiṣn de Binnah Qațāl ${ }^{12}$ es efectivamente el castillo de Penacadell, el río sobre el que está situado podría ser el Serpis, que corre en paralelo a la sierra por la vertiente sur. Tampoco debe descartarse la posibilidad de que el río que menciona al-Idrīsī sea el río Albaida o incluso el Bernisa, situados ambos en la vertiente norte de la sierra.

\subsection{Fuentes latinas y romances}

Las fuentes en las que se cita este topónimo están fechadas entre los siglos XI y XIV y comprenden distintos tipos de documentos, como son crónicas, asientos de cancillería e incluso un texto literario.

Los acontecimientos más antiguos mencionados en las fuentes están relacionados con la estancia del Cid en el levante peninsular, el cual, antes de tomar Valencia en 1094, asentó su poder en la región, ocupando una serie de lugares fuertes. Uno de ellos fue el castillo de PENNACATEL o PINNACATEL, en el que el Cid, según la Historia Ro-

11 Al-Idrīsī, ibid., 36. Considero que esta equivalencia es válida.

12 En un reciente trabajo, Rafael Azuar, tomando como base esta misma obra de al-Idrīisi, considera que la denominación de hișn podría hacer referencia a un distrito castral y no a un lugar fortificado concreto. Se apoya para ello en la inexistencia de dos hish mencionados por al-Idrīsī en al zona de Valencia; Turīs y al-Qalca. Vid. Azuar, R., "Ciudades y territorio en el Sharq al-Andalus", Ciudad y territorio en al-Andalus, 2 (2000), 481. Sin embargo, creemos que estos dos castillos sí existen y que los datos que da el geógrafo árabe son correctos. El castillo de Turís se encuentra en el punto XJ962614, mapa Cheste 28-28 (721), escala 1: 50.000, Mapa Militar de España, Servicio Cartográfico del Ejército, Madrid 19924. El castillo de Alcalá se encuentra en el punto YJ082563, mapa Llombay 28-29 (746), escala 1: 50.000, Mapa Militar de España, Servicio Cartográfico del Ejército, Madrid $1991^{4}$. Para el concepto de hiṣn en la obra Nuzhat al-muštāq de al-Idrīsī, véase Mazzoli-Guintard, Ch., "Hịsn, qal'a, qașaba ... chez al-Idrīsī", Qurțuba, 3 (1998), 101-107. 
derici, reconstruyó en 1091 los edificios que en él había y que habían sido destruidos poco antes por los musulmanes. Además levantó un muro inexpugnable alrededor de este lugar y en él instaló una guarnición bien abastecida de armas y víveres: "Quo in loco quendam castrum, qui dicitur Pennacatel, quod sarraceni funditus destruxerant, multis et firmis edificiorum munitionibus rehedificauit, atque muro inexpugnabili undique cinxit, firmiterque illud construxit. Tam militum quam peditum multitudine omnibus armorum generibus sufficienter munitum, prefatum castrum tandem nimium muniuit: panis etiam uini et carnis copia illud copiose repleuit» ${ }^{13}$.

Otra fuente medieval es la Crónica de Orderico Vital, la cual refiere la toma del castillo de PENECADEL en el año 1124 por parte de un grupo de caballeros aragoneses, francos, gascones y templarios, mandados, entre otros, por Rotrón de Alperche y Gastón de Bearne, al servicio de Alfonso I el Batallador. Éstos consiguen apoderarse de la fortaleza a pesar de las dos torres inexpugnables que la defienden y logran permanecer en ella durante varias semanas saqueando la región ${ }^{14}$. Finalmente la tropa se retira dejando en el castillo a sesenta soldados que poco después se enfrentan a un grupo de almorávides. Tras varios días de asedio se produce la batalla entre ambos bandos $\mathrm{y}$, después de todo un día de lucha, los almorávides son derrotados y se retiran de noche por caminos desconocidos para los hombres del castillo ${ }^{15}$.

\footnotetext{
${ }^{13}$ Historia Roderici apud Menéndez Pidal, R., La España del Cid, Madrid, 1929, II, 949. En este estudio sobre el Cid, Menéndez Pidal recopila el texto de varias crónicas que a su vez relatan este mismo episodio de la Historia Roderici referente a la destrucción del castillo y su reconstrucción. En ellas se menciona posiblemente este castillo, pero con distintos nombres: en la Crónica Particular del Cid se cita el castillo como "Pont Mentin", en la Crónica de 1344 se menciona como "Sant Martino" o "Sant Maria", y en la Crónica de Veinte Reyes aparece bajo la forma de "Peña Catir". Menéndez Pidal, R., ibid., p. 787. Para una aproximación a la actuación del Cid en la zona de Valencia y su relación con este castillo, véase Huici Miranda, A., Historia musulmana de Valencia y su región, II, Valencia, 1970, 36, 64, 70, 80 y 223-225.

14 Según Gual Camarena, esta expedición se llevó a cabo en 1124 y posiblemente tuvo como finalidad tantear el terreno para la gran expedición de Alfonso I del año siguiente a Andalucía, la cual se desarrolló entre septiembre de 1125 y junio de 1126 . Vid. Gual Camarena, M., "Precedentes de la Reconquista Valenciana", Miscelánea de Estudios Medievales, I (1952), 180. En cuanto a las dos torres hay que suponer que fueron construidas en tiempos del Cid o en época almorávide.

${ }_{15}$ Gual Camarena, M.: "Precedentes", 178-180. Este acontecimiento pertenece a la crónica latina de Orderico Vital y dice: "Tunc Rotro Comes Moritoniae cum Francis, et Episcopus Caesaraugustanus cum fratibus de Palmis, Guazso de Biara cum Gasconibus,
} 
Es posible que los hombres del rey aragonés también terminaran por desalojar la fortaleza de PENNA CATELLA, según se desprende de un documento firmado en $1124^{16}$. Al año siguiente, es decir, en 1125 , según los Anales Toledanos I, cuando Alfonso I el Batallador pasa por Valencia y Játiva para dirigirse a Murcia y Granada, toma Peña-Cadiella de nuevo ${ }^{17}$.

El Poema de Mio Cid también menciona Peña Cadiella como una peña fuerte ${ }^{18}$.

\author{
«ganada [à] a Xérica \\ priso a Almenar \\ assí fizo Çebolla \\ e Peña Cadiella \\ con aquestas todas
}

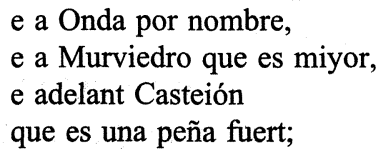

Penecadel, ubi sunt duae turres inexpugnabiles, munierunt, et sex septimanis tenuerunt. Tandem pugnantes contra Amorgam Regem Valentiae per Satinam (Sativám) urbem convenerunt: sed pagani antequàm ferirentur, fugerunt. Relictis autem in munitione Penacadel LX. Satellitibus, redierunt. Sed Amoravii et Andelucani de Affrica missi à Rege Alis, filio Insted, eis obviaverunt, triduoque in castro Serraliis obsederunt. Cristiani verò his tribus diebus peccatorum suorum poenitentiam egerunt, jejunaverunt, Deum invocantes XVIII. Kal. Septembris pugnaverunt, et adminiculante caelesti virtute post diurnum certamen, cum sol occumberet, vicerunt: sed fugientes paganos, nocturna formidantes pericula, per incognita itinera diu persequi non ausi fuerunt" en Flórez, H., España Sagrada, Madrid, 1777, X, apéndice VIII, 605-606.

${ }_{16}$ "Facta carta era $M^{a}{ }^{a} C{ }^{a} L X{ }^{a} I I .^{a}$, in illo anno venerunt de illa hoste de Penna Catella", Arco, R. del, "Referencias a acaecimientos históricos en las datas de documentos aragoneses de los siglos XI y XII", EEMCA, III (1947-1948), 321. En este documento el vizconde Gastón de Bearne, tras regresar con la tropa del rey Alfonso I, da a Arnaldo de Lavedán unas casas en Zaragoza y un huerto en el arrabal. Confirma la donación Centullo, hijo del vizconde.

17 "1125 Fue presa Peña-Cadiella Era MCLXIII", Anales Toledanos I, apud Flórez, H., España Sagrada, Madrid 1767, XXIII, 388; cfr. Anales Toledanos I, en Crónicas Latinas de la Reconquista. Estudios prácticos de latín medioeval, ed. Huici, A.,Valencia 1913, I, 343. Para una bibliografia relativa a esta expedición, véase Serrano, D., "Dos fetuas sobre la expulsión de Mozárabes al Magreb en 1126", Anaquel de Estudios Árabes, 2 (1991), 163 y ss., nota 1.

18 Poema de Mio Cid, ed. Michael, Ian, Madrid, 1987, 172. En el poema se menciona Peña Cadiella en tres ocasiones, en los versos 1163, 1164 y 1330. En el verso 1330 cabe interpretar "peña fuert" como "lugar fortificado", puesto que el autor del poema lo menciona junto a otros enclaves amurallados. A este respecto, Menéndez Pidal dice que “.... peña es sinónimo de 'castillo', o peña fuert, como dice el Cantar en sus versos 1330 y 2691". Vid. Cantar de Mio Cid. Texto, gramática y vocabulario, Madrid, 1946, III, 1171. 


\subsection{Fuentes catalanas}

Por lo que a fuentes catalanas se refiere, éstas pueden dividirse en dos grupos.

En el primero se encuentran una serie de documentos emitidos entre 1258 y 1276 por Jaime I. También en la segunda mitad del siglo XIII este castillo es mencionado en distintos asientos, por los que se sabe que de Penacadel o Penacadell dependían otros castillos y alquerías, entre los que se encontraba el de Carbonera ${ }^{19}$. En el último cuarto del siglo XIII y durante el siglo XIV se siguen mencionando los castillos de Penacadell y Carbonera en diversos documentos reales ${ }^{20}$.

En el segundo grupo y perteneciente también al siglo XIII, tenemos la Crònica o Llibre dels Feits. En esta crónica se relatan los hechos del rey Jaime I y de ella nos interesan especialmente los capítulos 370 y sobre todo el 371. En este último capítulo se encuentra el texto en el que se narra el desarrollo de la lucha que tuvo lugar por conquistar el castillo de Penacadell. De dicho texto y de su análisis nos ocuparemos más adelante.

\section{Propuestas de localización}

Tres son a mi juicio los trabajos fundamentales dedicados a la localización del castillo. El primero de estos estudios fue el llevado a cabo por Ribera en 1886, quien lo identificó con el castillo de Carbonera, situado en la vertiente norte de esta sierra, entre los términos de Otos y Beniatjar, a 630 metros de altitud ${ }^{21}$. Dos años más tarde, y a la

19 Martínez Ferrando, J. E., Catálogo de la documentación relativa al antiguo reino de Valencia contenida en los registros de la Cancillería Real del Archivo de la Corona de Aragón. I, Jaime I el Conquistador, Madrid, 1934, documentos n. ${ }^{\circ} 142,179,181,460$, $467,868,888,1480,1481,1604,1835,1920,1922$ y 2058; Chabás, R., "Sección de documentos", El Archivo, II (1887-1888), ed. facs. Alicante, 1986, 340, doc. 19.

${ }^{20}$ Conde Delgado de Molina, R., "Documentos para la historia del reino de Valencia. Serie "Gratiarum" de Jaime II (1290-1304)", Primer Congreso de Historia del País Valenciano, I, Valencia, 1973, 222 y 223; Chabás, R., "Sección de documentos", El Archivo, II (1887-1888), ed. facs. Alicante, 1986, 341, doc. 20 del año 1324; Guichard, P., "Un toponyme historique", p. 40, n. 14, doc. del año 1358; J. Coromines señala la existencia de un documento con fecha de 1364, vid. Onomasticon Cataloniae, Barcelona, 1995, III, 210, s.v. "Cambradasa".

${ }^{21}$ Ribera, J., "Un rey ignorado en la Contestania. El Cid en Benicadell", El Archivo, I (1886), ed. facsímil, Alicante, 1985, 97-102. 
luz de nuevos documentos, rectificaría su primera hipótesis, señalando que el castillo de Benicadell y el de Carbonera eran dos castillos distintos ${ }^{22}$.

La segunda propuesta es de Menéndez Pidal, que lo identifica con el castillo de Carbonera y considera que los restos que se encuentran en $E l$ Pic pertenecen a una atalaya que servía a varios castillos ${ }^{23}$. Esta opinión ha sido aceptada y seguida por la mayoría de los estudiosos que se han ocupado de la figura del Cid.

La tercera de estas investigaciones, la más reciente y también la más documentada es la de Guichard, el cual concluye que el castillo se encontraba en $\mathrm{El} \mathrm{Pic}{ }^{24}$.

Aparte de estos trabajos, Pla Ballester considera que este topónimo no designaría un castillo en concreto, sino un conjunto de fortificaciones asentadas en dicha sierra ${ }^{25}$.

Los estudiosos que se han interesado por este castillo coinciden a la hora de destacar su importancia y están de acuerdo en que el recinto fortificado debió tener un tamaño considerable; pero la falta de restos arqueológicos ha hecho que algunos de ellos desechen la posibilidad de ubicarlo en El Pic y hayan optado por situarlo en otros lugares, en los que aún subsisten restos arquitectónicos importantes, a pesar de saber que esta localización no era acorde con los datos ofrecidos por los documentos medievales.

Dicho esto, convendría intentar aclarar las cuestiones que han llevado a algunos autores a desechar esta posible localización en El Pic: la primera, el tamaño del castillo; la segunda, la falta de restos arquitectónicos.

Las dos únicas fuentes que nos dan algún detalle del recinto, aunque sin mencionar su tamaño, son la Historia Roderici y la Crónica de Orderico Vital. En la primera se dice que el Cid reconstruye muchos y fuertes edificios a los que rodea de un muro y que aprovisiona

22 Ribera, J., "Correcciones y notas", El Archivo, II (1888), 249-251.

${ }^{23}$ Menéndez Pidal, R., Cantar de Mio Cid. Texto, gramática y vocabulario, Madrid, 1945, II, 790, s.v. "Peña Cadiella". Sin embargo una serie de documentos emitidos por Jaime I, entre 1258 y 1276, demuestran claramente que el castillo de Penacadell y el de Carbonera eran dos castillos distintos. Cfr. Martínez Ferrando, J. E., Catálogo, documentos núms. 179, 181, 868, 1480, 1835, 1920 y 1922.

${ }^{24}$ Guichard, P., "Un toponyme historique", 37-47.

25 Pla Ballester, E., Gran Enciclopedia de la Región Valenciana, Valencia, 1973, VIII, 233-234, s.v. "Penya Cadiella". 
el lugar de todo lo necesario. En la segunda se señala la existencia de dos torres inexpugnables y añade que en el castillo permaneció un grupo de sesenta soldados ${ }^{26}$.

Si se recorre con detenimiento el lugar, teniendo en cuenta la superficie total en la que aflora la roca y en la que es posible fijar sólidamente cualquier cimentación, vemos que la extensión resultante es más que suficiente para albergar un castillo de notables proporciones, mayor incluso que la mayoría de los castillos de la zona, a pesar de lo abrupto del terreno y de las dificultades para su construcción en tan enriscado lugar. Recordemos que parte del material necesario para la construcción del recinto fortificado que el Cid reedifica, las piedras, ya estaban en el lugar formando parte de los muros de un asentamiento anterior. Aunque no se conocen cuáles fueron las técnicas empleadas en su construcción, ni en las sucesivas reformas, reparaciones y obras de mantenimiento que debió sufrir en distintas ocasiones, los restos encontrados parecen indicar que a lo largo de su existencia se empleó la mampostería, trabada o no, con mortero de cal, tapial, ladrillo y teja. Además, hay que añadir que es probable que se usaran elementos de madera y que incluso hubiera dependencias o sectores adyacentes al castillo levantados simplemente de piedra seca.

En cuanto al abastecimiento de agua, la presencia actualmente de un único pozo ${ }^{27}$ en el sitio más resguardado de la cumbre no significa que no existieran más aljibes hoy desaparecidos. Dicho pozo debió tener funciones de aljibe que recogería el agua de lluvia o incluso nieve derretida. Dada la pendiente del terreno, el castillo pudo estar dispuesto en terrazas en las que hubiera alguna cisterna más y que inclu-

\footnotetext{
26 Ésta es una cantidad considerable de hombres si se tiene en cuenta que un siglo y medio más tarde, en 1273, el rey ordena al alcaide de este castillo, Juan de Montsó, tener quince hombres para su custodia. Cfr. Martínez Ferrando, J. E., Catálogo, doc. 1481, 324. Este grupo de quince hombres puede ser considerado a su vez una guarnición importante si la comparamos con los "seixanta cavallers e escuders ab armes" que, bajo el mando de Guillem de Montcada, Jaime I destinó al castillo de Játiva al iniciar la campaña contra al-Azraq. Vid. Crònica o Llibre del Feits, Barcelona, $1988^{2}$, ed. F. Soldevila cap. 367,312 . En el año 1249 el rey Jaime I concedió también a Guillem de Montcada el castrum y la villa de Peñíscola en beneficium con la condición de mantener en ella una guarnición de veinte hombres. Vid. Guichard, P., Les musulmans de Valence et la reconquête (XI. ${ }^{\mathrm{e}}$-XIII. ${ }^{e}$ siècles), Damasco 1991, II, 409.

27 J. A. Cavanilles dice que tenía una profundidad de veinte palmos y que a catorce había agua fresca pero blanda. Observaciones sobre la historia natural, geografia, agricultura, poblacion y frutos del Reyno de Valencia, Madrid, 1797 (repr. fac.), Valencia, 1978, II, 134.
} 
so las tinajas, cuyos fragmentos tanto abundan, sirvieran en una época determinada para almacenarla en caso de necesidad.

La evidente falta de restos arquitectónicos llama la atención y, si no se conoce el lugar, resulta difícil entender cómo un castillo de esta importancia ha podido desaparecer sin dejar prácticamente ninguna huella de su existencia. Esta falta de restos puede deberse a varios factores:

1) Las muy pronunciadas pendientes de la montaña que terminan en grandes precipicios, al pie de los cuales hay también fragmentos de céramica.

2) Los terremotos que esta zona ha sufrido ${ }^{28}$.

3) Los incendios y las inclemencias climatológicas a las que el lugar se encuentra expuesto debido a su altitud.

4) Quizás habría que añadir a estos agentes naturales, como causantes de la desaparición del castillo, la intervención del hombre y las circunstancias históricas:

a) Es posible que se destruyeran voluntariamente aquellas partes del castillo que no interesaba mantener, el cual, según épocas y necesidades, pudo tener distintos tamaños y que en el siglo XIV no fuera más que un recinto de menor tamaño respecto a lo que había sido en algún momento anterior. Pensemos que la situación político-social y militar de la región no era la misma en el siglo XI que en el XIII o incluso el siglo XIV.

b) Aunque hasta la fecha no se conoce cuál pudo ser el final del castillo, no debe descartarse la posibilidad de que en un momento determinado, más allá de la segunda mitad del siglo XIV, se decidiera arrasarlo. Téngase en cuenta la importancia que le concedieron los distintos poderes que dominaron la región durante la Edad Media, tal $\mathrm{y}$ como parecen demostrarlo las sucesivas luchas por poseerlo, y añadamos las dificultades que desde él se podían crear en caso de caer en manos del enemigo que fuese ${ }^{29}$.

${ }^{28}$ Esta es una región que ha sufrido numerosos temblores de tierra y los últimos que han afectado la sierra son los ocurridos el 1 de julio de 1945, el 18 de diciembre de 1998 y el 3 de enero de 1999. Vid. Diario Levante (4 de enero de 1999), 27. Véase además Rodríguez de la Torre, F., "Catálogo sísmico de la actual provincia de Alicante (hasta final del siglo XVIII)", Revista del Instituto de Estudios Alicantinos, 30 (1980), 2..$^{\circ}$ cuatrimestre, 107-133.

${ }_{29}$ Sirvan como ejemplo de la importancia que se le concedía a este lugar los versos (n. ${ }^{\circ}$ 1164-6) del Poema de Mio Cid, edición I. Michael, 160: "Quando el Çid Campeador ovo Peña Cadiella / ma[1] les pesa en Xátiva e dentro en Guiera, / non es con rrecabdo el dolor de Valençia". 


\section{El entorno geográfico de la Sierra del Benicadell}

Para proseguir me parece necesario hacer una descripción detallada, en la medida de lo posible, de la situación de esta sierra (fig. 1). Respecto a su entorno, la sierra de Benicadell tiene un tamaño considerable, unos siete kilómetros de longitud, y una orientación de oeste a este. Arranca al oeste en el Port d'Albaida desde una altitud de 600 metros; se eleva en un kilómetro hasta los 900 metros. Desde aquí, y durante algo más de tres kilómetros, las cotas más altas de la sierra se mantienen entre los 900 y 1.000 metros de altitud. En este lugar se encuentra El Alt del Benicadell (1043 m), también conocido como Alt de la Nevera por la existencia de una cava para la recogida de nieve. A 650 metros de este sitio, siempre hacia el este, se encuentra el punto más alto de esta cordillera, El Pic $(1.104 \mathrm{~m})$, que es un impresionante escarpe rocoso en forma de cuchilla. Desde esta cumbre la visibilidad es excepcional, ya que pueden verse montañas, valles y

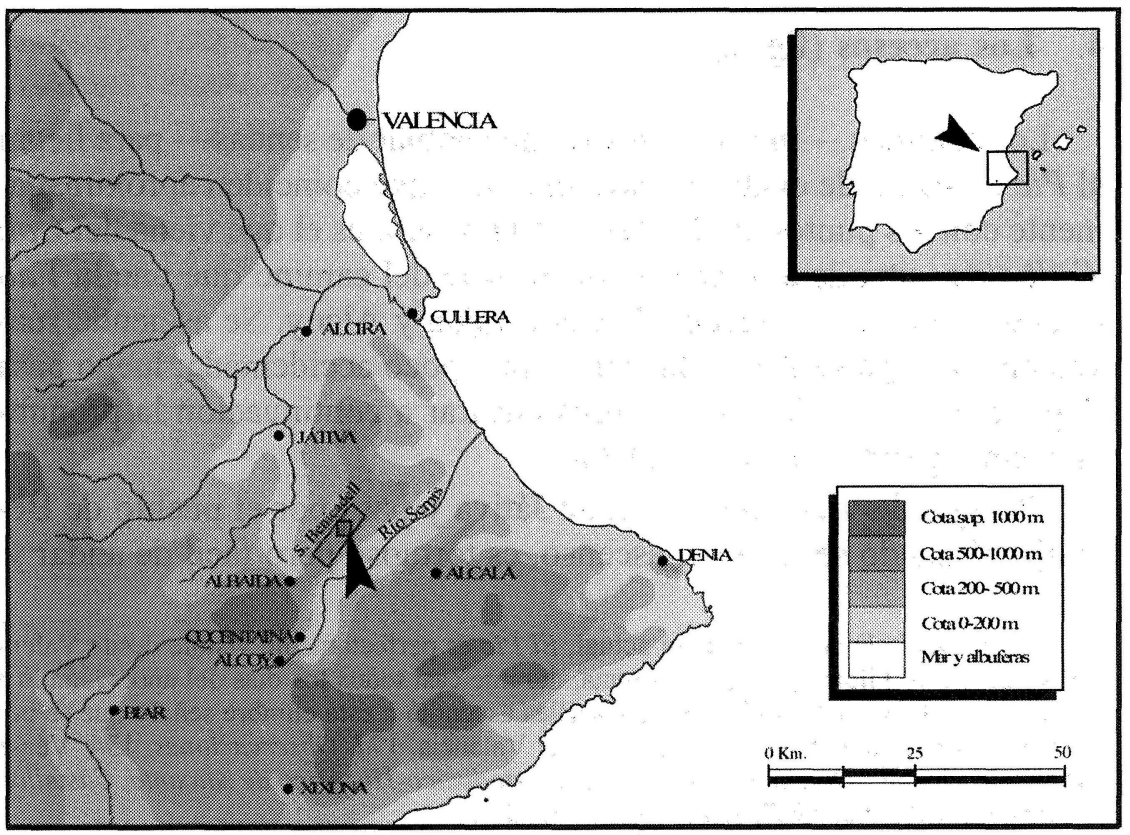

FIG. 1.-Situación de la Sierra del Benicadell 
poblaciones a decenas de kilómetros de distancia ${ }^{30}$. A partir del Pic la altura va disminuyendo y a menos de un kilómetro se encuentra otro escarpe rocoso conocido como El Guatleró $(775 \mathrm{~m})$. Siguiendo hacia el este, la altura continúa disminuyendo para llegar al puerto llamado Coll del Raconet.

Esta sierra es, pues, un gran muro natural que separa la Vall d'Albaida (Valencia) de la cuenca alta del río Serpis y la Foia de Cocentaina (Alicante) y solamente es franqueable por sus extremos, en donde se encuentran los collados citados y en los cuales nacen otras sierras, como la de Agullent y la de Mariola, al oeste, y la de Ador, al este. Estos collados son paso obligado y único para llegar a la tierras situadas a ambos lados de la sierra. Así, la cima de esta pequeña cordillera está situada en su parte oriental, donde alcanza su máxima altitud, El Pic, el cual está flanqueado por El Alt y El Guatleró (fig. 2).

\section{Los accesos (fig. 2)}

Los caminos - más bien habría que hablar de sendas - para llegar al Pic arrancan de cuatro lugares distintos que coinciden aproximadamente con los puntos cardinales ${ }^{31}$. El primero es el que viene del Coll d'Albaida, situado al oeste, es decir, sale del camino que une la Vall d'Albaida con las ciudades de Cocentaina y Alcoy. Se asciende suavemente a la parte alta de la sierra, muy poco accidentada; luego pasa al pie del Alt del Benicadell, para encarar a continuación la pronunciadísima pendiente oeste del Pic.

El segundo viene del norte, de Játiva y pasa por el pueblo de Beniatjar. Cuando se inicia el ascenso, es tortuoso pero fácil de andar y,

\footnotetext{
${ }^{30}$ A pesar de la contaminación actual, El Pic es perfectamente visible desde Valencia, a más de 60 kilómetros en línea recta, durante casi todos los días del año. Cuando a finales del siglo XVIII Antonio José Cavanilles ascendió a esta cumbre señaló que se podía ver la Albufera e incluso los edificios de Valencia. Vid. Observaciones, 134. Véase también Madoz, P., Diccionario Geográfico-Estadístico-Histórico de Alicante, Castellón y Valencia, Valencia, 1987, I, 12, s.v. "Albayda".

31 Para conocer todos estos caminos de acceso de forma detallada, con distancias y duración de los trayectos, véase Cebrián, R., Las montañas valencianas. I, Valencia, 1981, 102-117 y también del mismo autor Las montañas valencianas. IV, Valencia-Paterna, 1991, 116-127.
} 


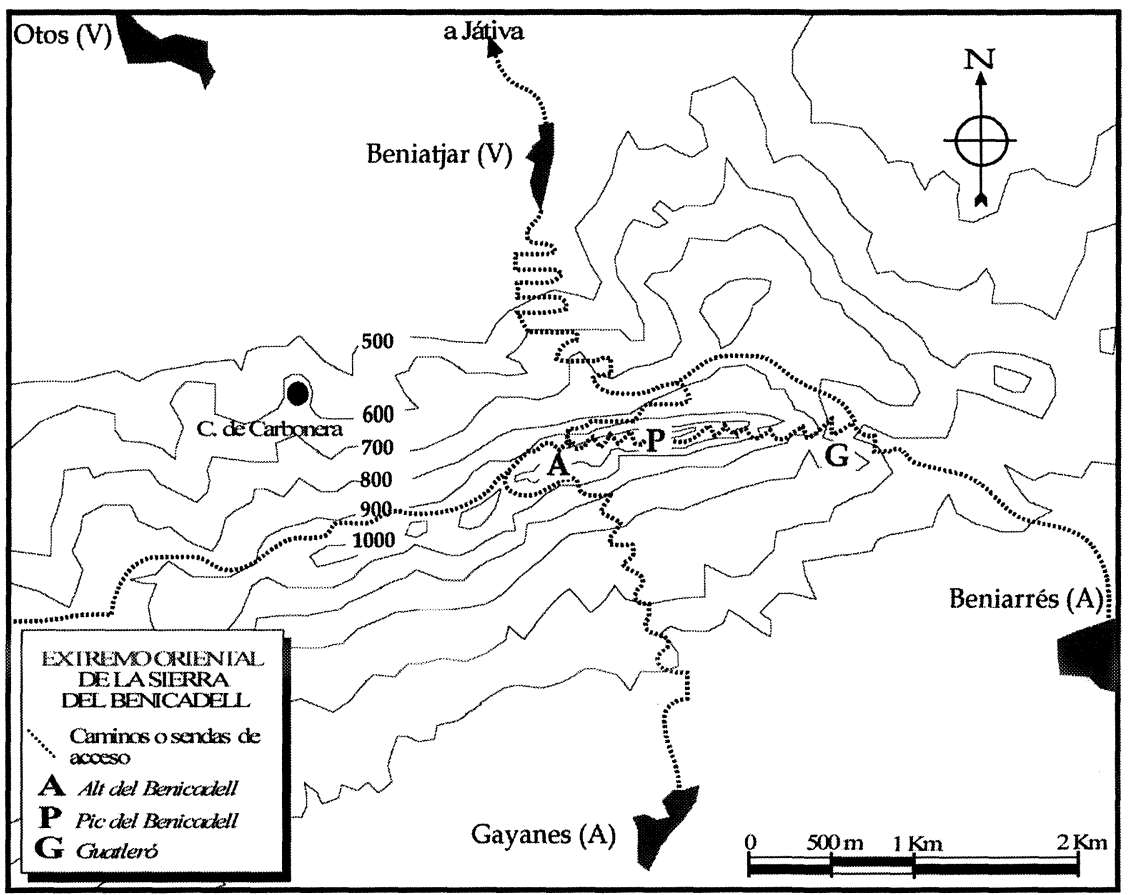

FIG. 2.-El extremo oriental de la sierra y las sendas hasta El Pic

al llegar a la parte alta de la sierra, se une con la senda que viene de la ciudad de Albaida al pie del Alt del Benicadell ${ }^{32}$.

El tercero es el más abrupto y viene del este, pasa entre El Guatleró y la masa rocosa que conforma la cuchilla que baja desde el Pic del Benicadell. Desde este punto, y dado el desnivel, el camino serpentea hasta la cumbre. Estas dos últimas sendas están unidas entre sí por otra.

El cuarto acceso es el más difícil y se inicia en Gayanes. Parte en dirección norte hasta llegar al pie del acantilado sur del Alt del Benicadell, desde donde sigue hacia el oeste hasta encontrar un paso entre las rocas que permite llegar a un punto situado al oeste del Alt del Be-

32 Debido a la presencia en este lugar de la cava para almacenar nieve, construida probablemente entre los siglos XVI-XVIII, esta antigua senda pudo sufrir algunas modificaciones con el fin de facilitar el paso de acémilas cargadas de hielo, tal y como parecen demostrarlo algunos muros de contención levantados para evitar su rápido deterioro. 
nicadell, en el que se une a la senda antes mencionada que viene desde el Coll d'Albaida.

\section{Datos arqueológicos}

En mis repetidas visitas al extremo oriental de esta sierra he recorrido en distintas ocasiones tres yacimientos medievales situados en puntos no muy alejados entre sí. Dos de ellos son conocidos, El Guatleró y El Pic del Benicadell, tal y como lo demuestran las referencias bibliográficas existentes. Sin embargo, existe un tercero, El Alt, que localicé casualmente en 1982 junto a Salvador Climent. La falta de referencias bibliográficas sobre este punto, la inexistencia de catas clandestinas y la ausencia de escarbaduras dejadas por los buscadores de metales me llevan a pensar que afortunadamente este yacimiento sigue siendo desconocido (figs. 3, 4 y 5).

A continuación hago una somera descripción de cada uno de los yacimientos, no sin antes señalar que la cronología que ofrezco debe tomarse con toda precaución, ya que los restos cerámicos que se describen y en los que me baso para ofrecer una datación aproximada provienen o han sido vistos en la superficie de estos yacimientos, con todo lo que esto implica de falta de rigor científico en la toma de muestras. Téngase también en cuenta que estas prospecciones superficiales, no sistemáticas, pueden ser la causa de que falten determinadas tipologías cerámicas. Aparte de señalar que éstas están muy fragmentadas y deterioradas, con los consiguientes problemas de adscripción tipológica que de ello se derivan, he de añadir que sólo he dibujado las provenientes del Alt. En cuanto a los otros dos yacimientos, he recogido algunas muestras, pero me he limitado fundamentalmente a estudiar sus materiales sobre el terreno ${ }^{33}$.

33 Tal vez éste no sea el lugar adecuado para incluir los dibujos que he hecho de los fragmentos de cerámica más representativos encontrados en la superficie del Alt, pero considero que pueden ser muy útiles para los investigadores interesados en este tema. Téngase en cuenta que muchos hallazgos sólo son conocidos a través de referencias en las que se ofrecen datos sobre determinadas tipologías o formas - de variada nomenclatura-, que además estos materiales pueden encontrarse, en el mejor de los casos, almacenados en los fondos de uno o varios museos y que desde allí muy difícilmente serán publicados porque no provienen de una excavación llevada a cabo con rigurosos criterios científicos. Estos materiales se encuentran depositados en el Museo Municipal de Oliva (Valencia) con las signaturas: Alt. FA-III-20; AB 00/2; G 00/3; PB 00/4. 


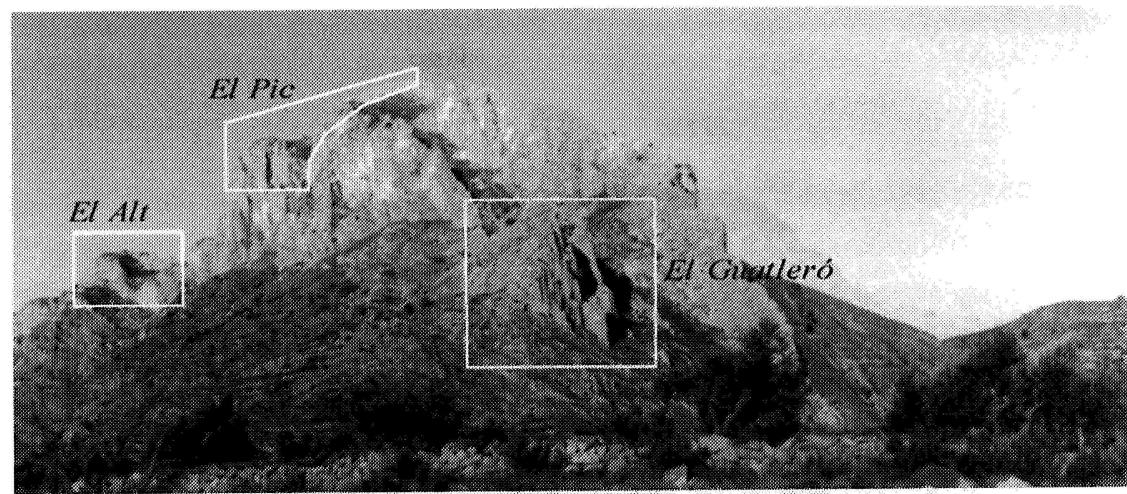

FIG. 3.-El extremo oriental de la sierra de Benicadell visto del sureste y la situación de los tres yacimientos

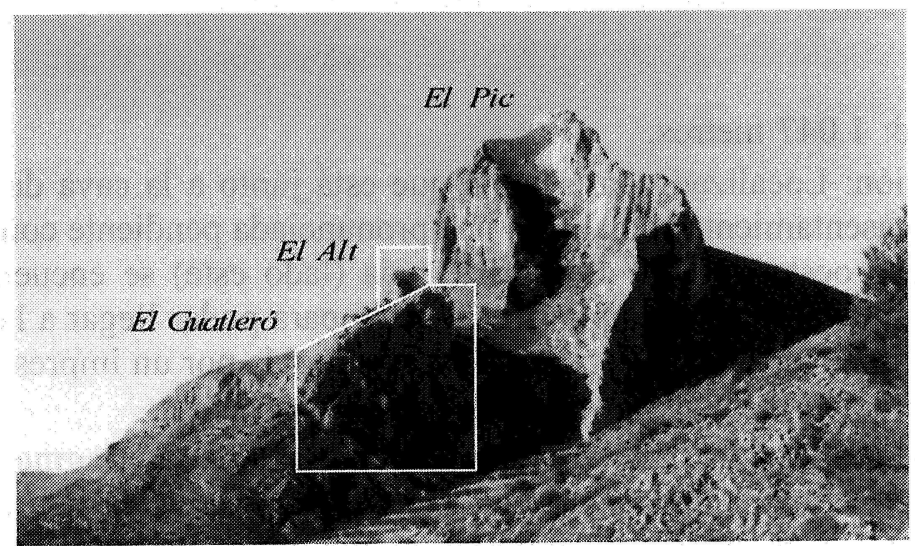

FIG. 4.-El extremo oriental de la sierra visto desde el este

\subsection{El Alt del Benicadell o Alt de la Nevera (A):}

Municipio: Gayanes (Alicante).

Localización: Cartografía Militar de España, Mapa General, serie L, 1991, E. 1: 50.000, Alcoy 29-32 (821), punto 30SYJ246014. Mapa Topográfico Nacional de España, Muro de Alcoy 821-I (57-63), E. 1: 25.000, Instituto Geográfico Nacional, Madrid 1997 (1. ${ }^{\mathrm{a}}$ ed.), punto 72463014 . 


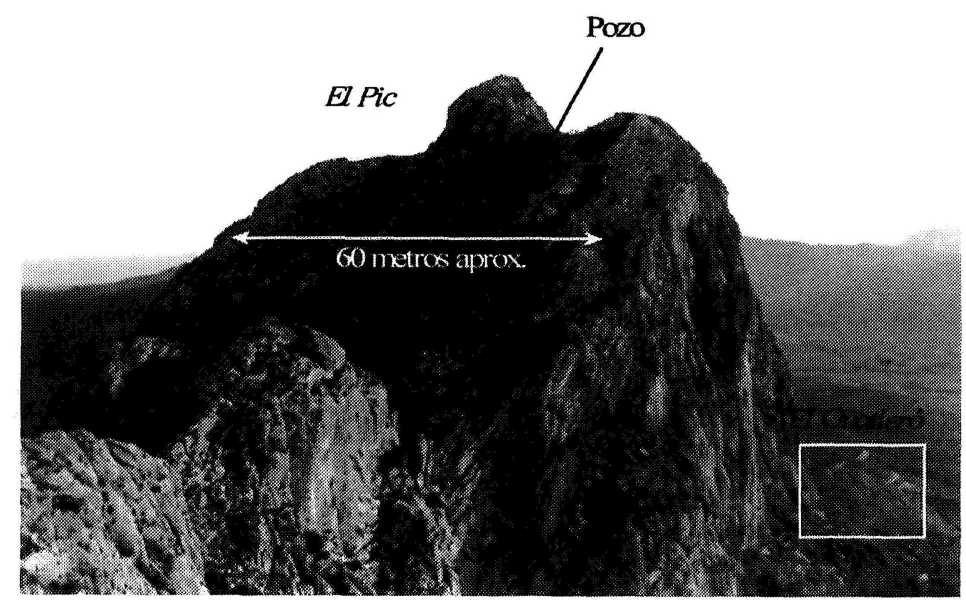

FIG. 5.-El Pic y El Guatleró vistos desde El Alt

Altitud: 1.047 metros.

Situación: Localizado en la loma que está junto a la cava de nieve, este asentamiento se halla en una pronunciada pendiente con orientación oeste-este, en cuya parte baja (lado este) se encuentra un acantilado y también un estrecho paso para poder llegar a la senda que conduce al Pic. Esta loma está protegida por un impresionante acantilado al sur y por un escarpe rocoso al norte.

Materiales: (Todos muy fragmentados). Unos pocos fragmentos de ataifor con pie anular decorados en verde y manganeso. Otros con melado y manganeso, cubiertas monocromas en verde, melado, blanco con trazos en verde y combinación verde interior con melado exterior. Dos fragmentos de base de ataifor de pie anular con moldura destacada ${ }^{34}$. También jarrito-a, marmita, jarro-a, redoma, candil de piquera y tapadera. Hay una presencia abrumadora de fragmentos de tinaja con cordones aplicados (figs. 6 a 10). Varios clavos de hierro y una hoja del mismo metal. Fragmentos de teja.

34 Dos fragmentos de pie de ataifor, con marcados anillos exteriores en la zona de engarce del pie con la pared del plato, pueden corresponder a las formas IIIb (1) o IVa (1). Vid. Azuar, R., Denia islámica. Arqueología y poblamiento, Alicante, 1989, 242 y 244 . 
Alt del Benicadell

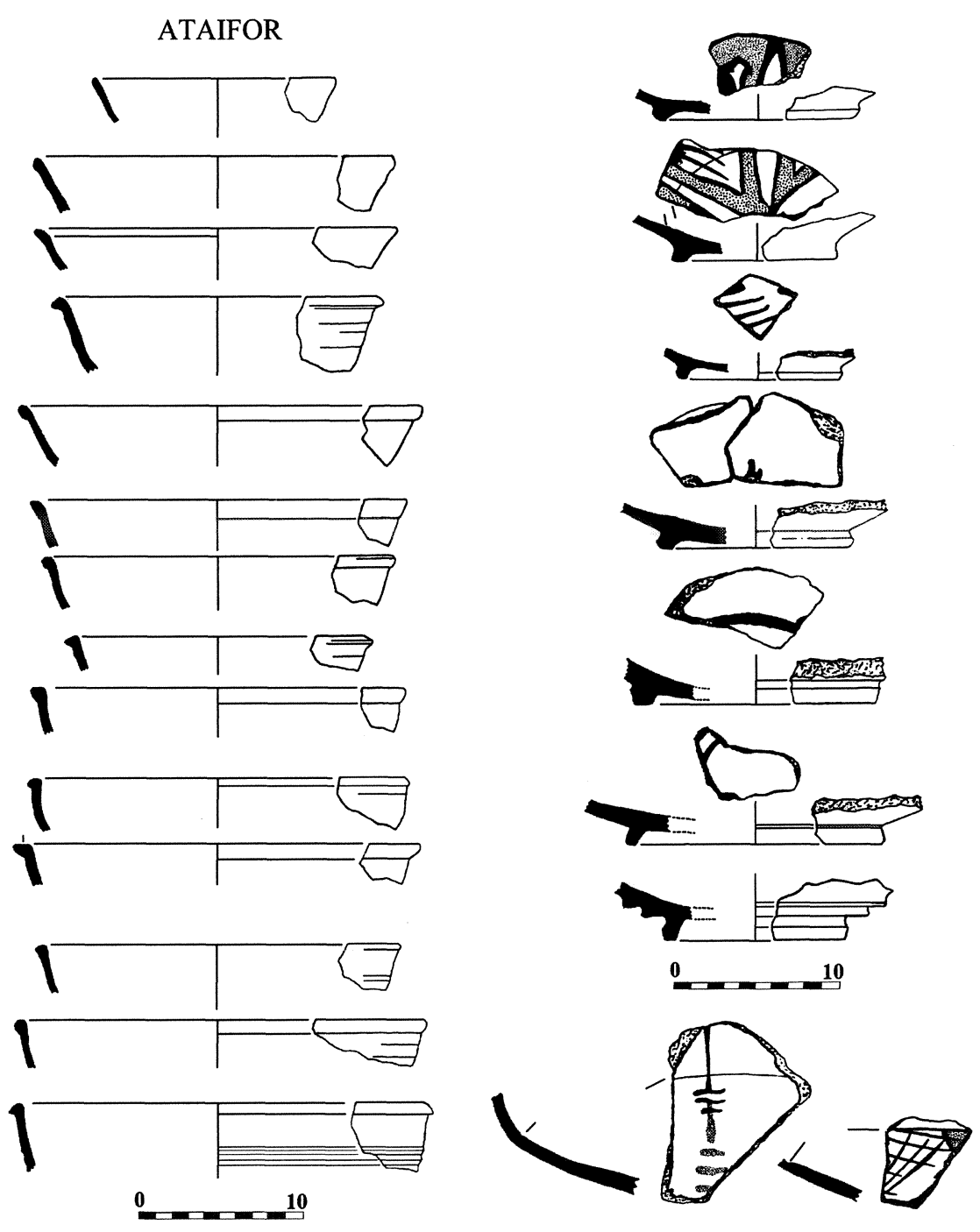

FIG. 6.-Ataifor 

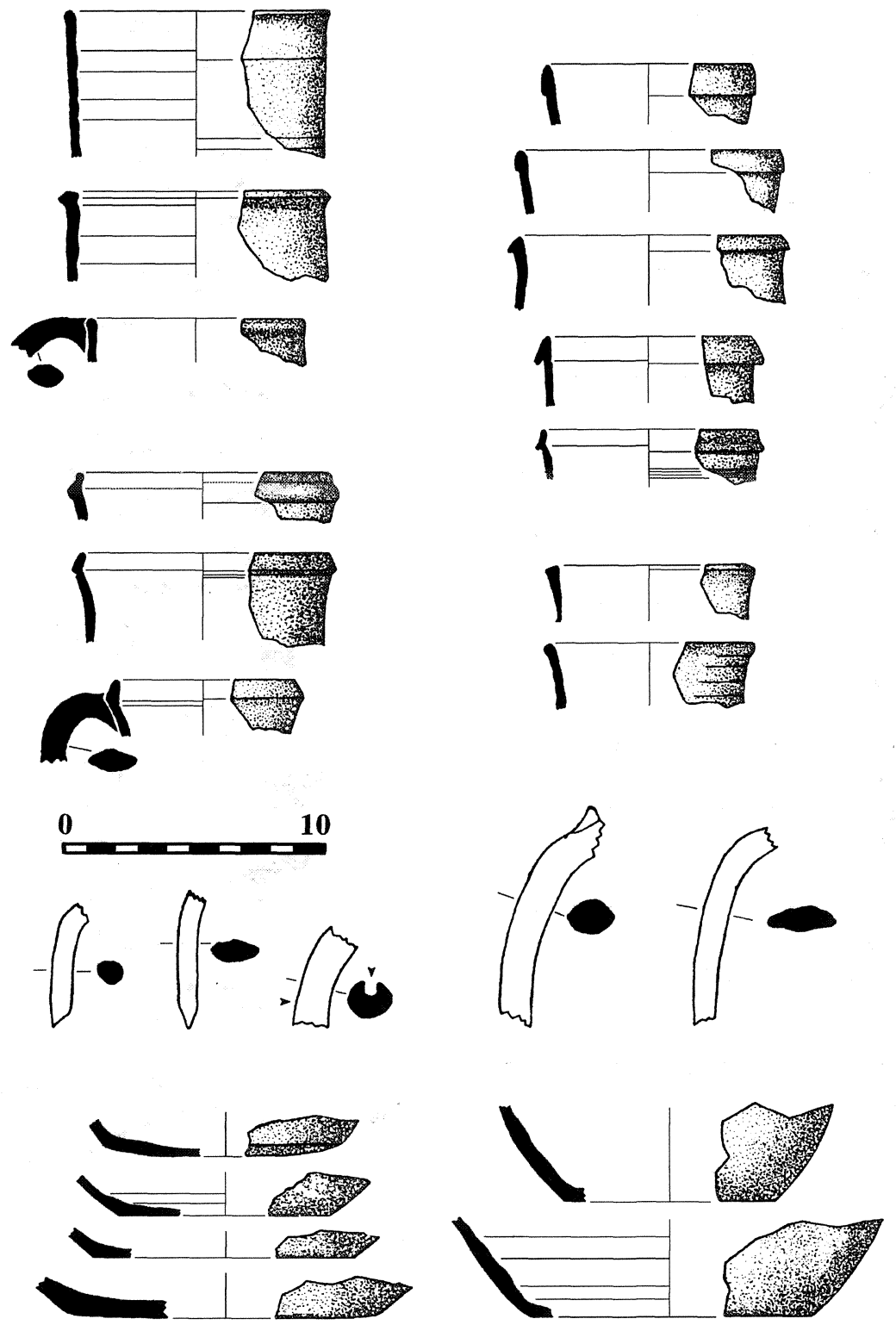

FIG. 7.-Jarrita-Jarrito 

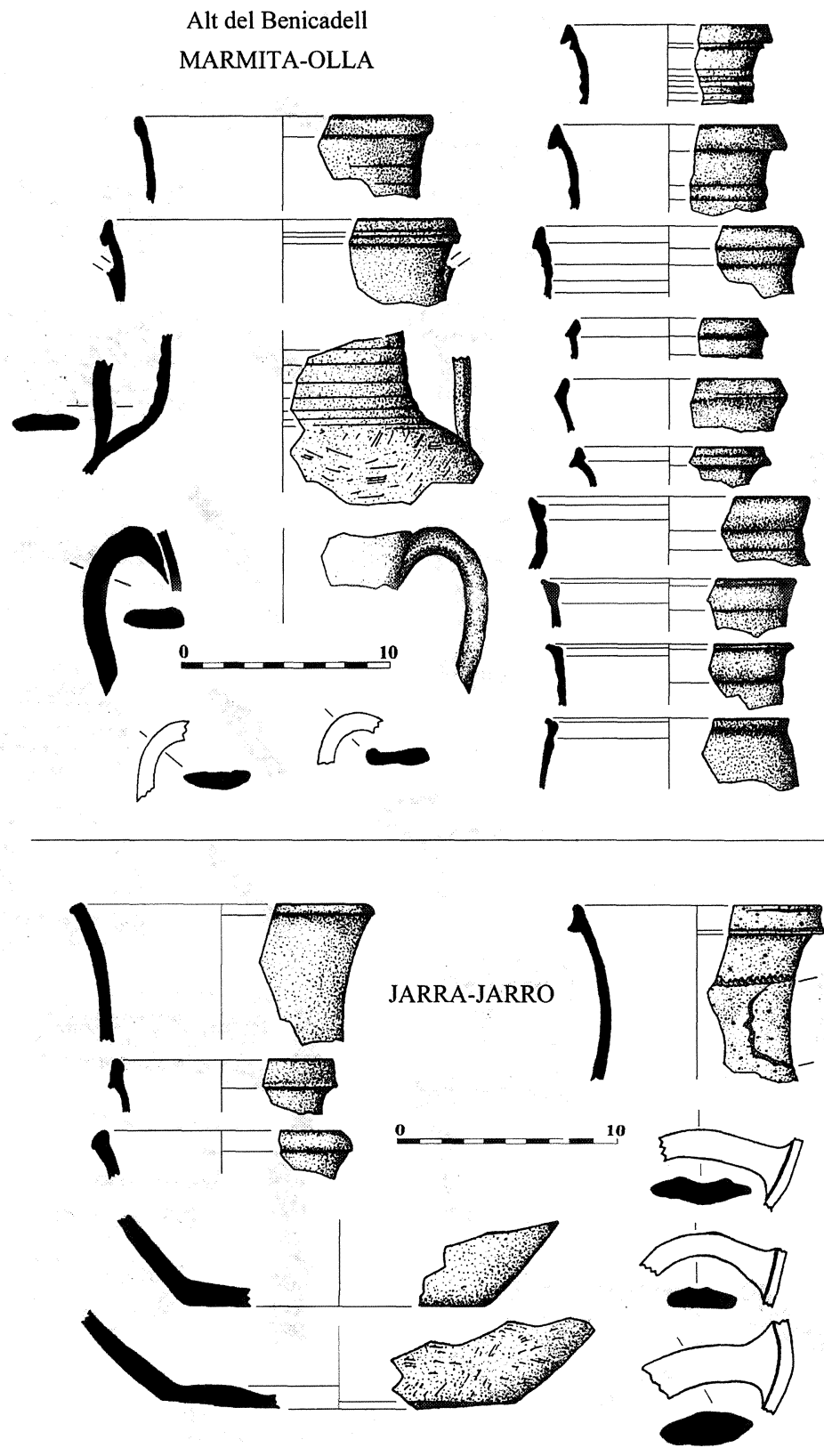

FIG. 8.-Marmita-Olla. Jarra-Jarro 
Alt del Benicadell TINAJA

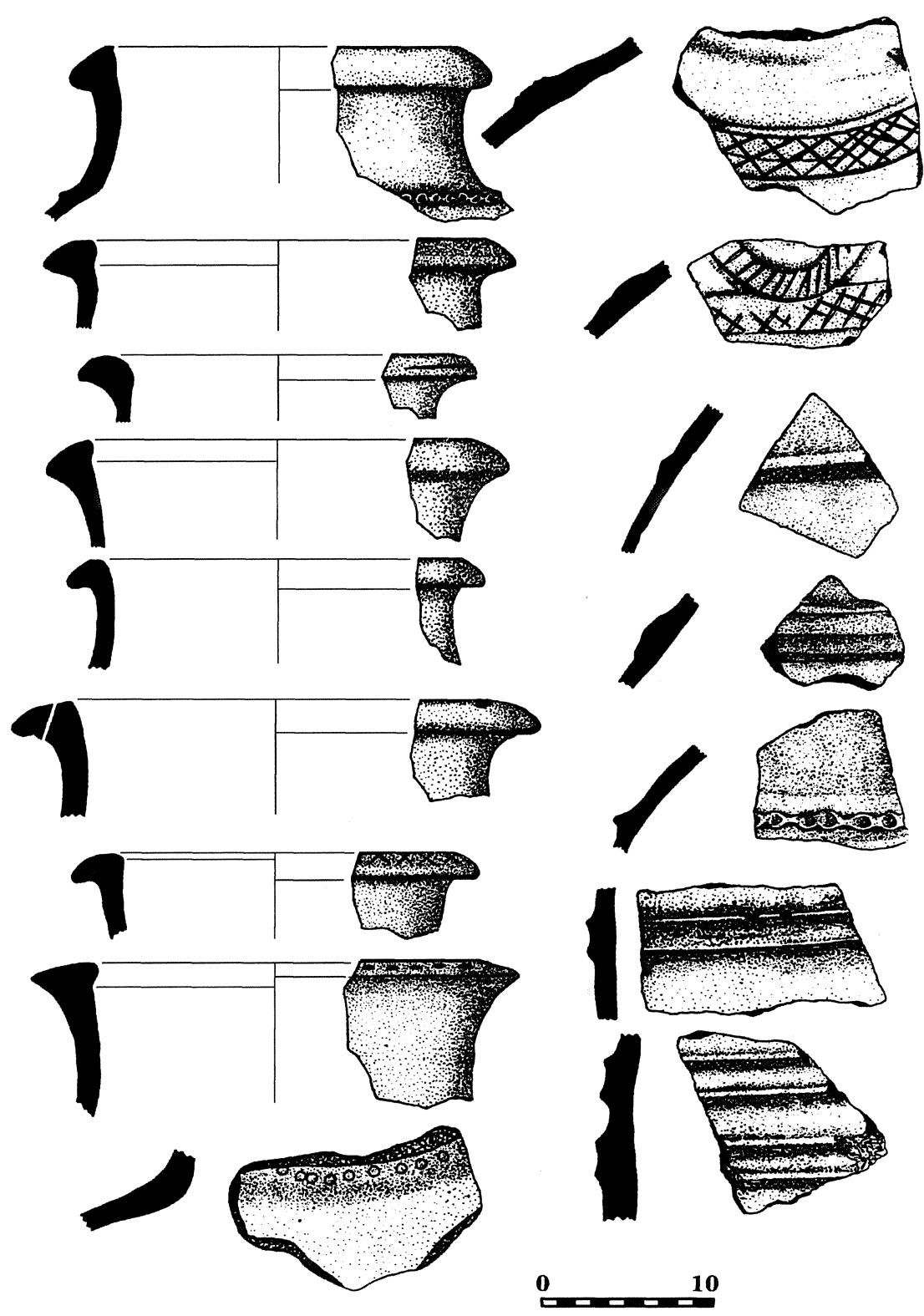

FIG. 9.-Tinaja 

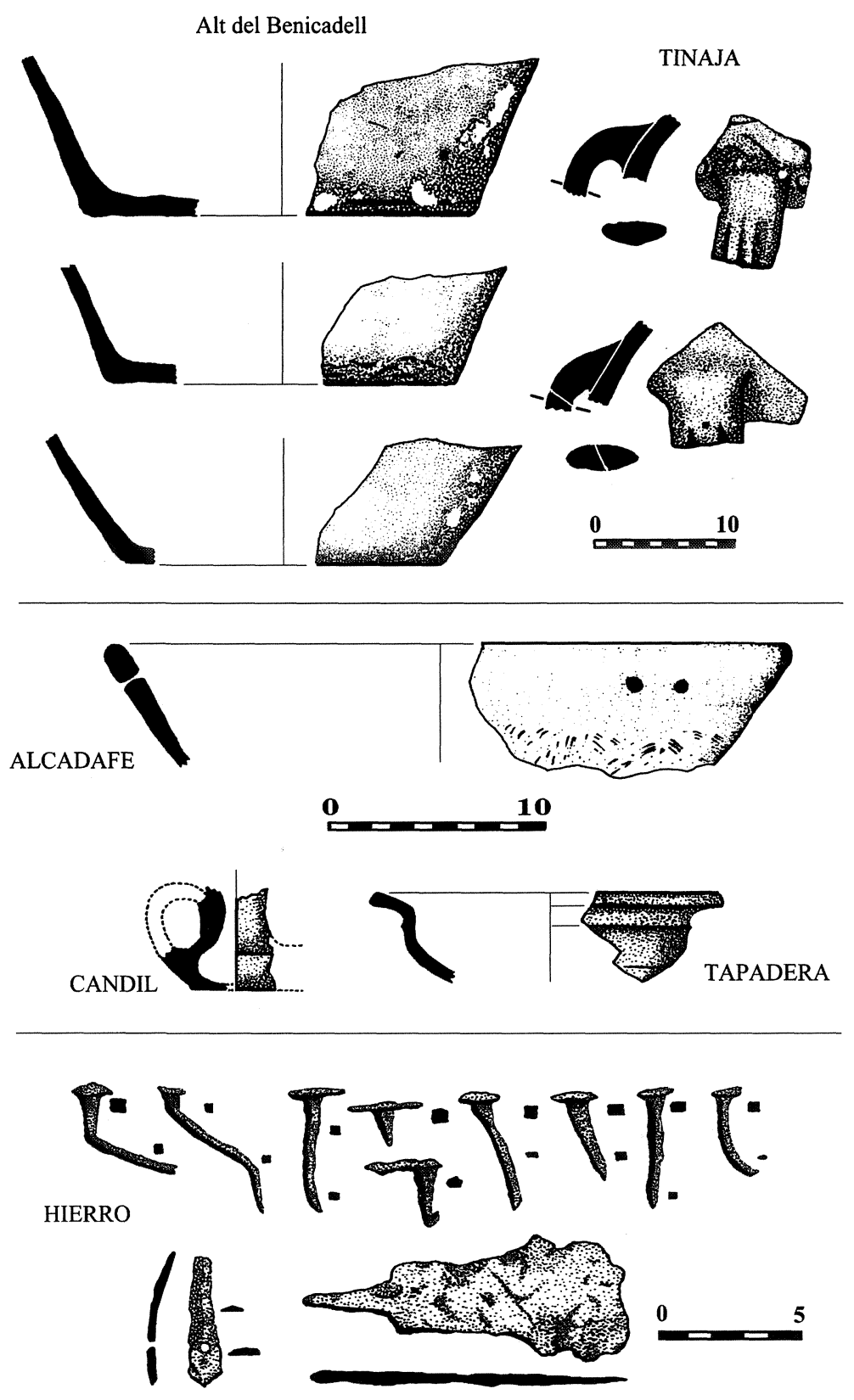

FIG. 10.-Tinaja. Alcadafe. Candil. Tapadera. Hierro 
Restos arquitectónicos: La maleza recubre, en el lado norte, restos de lo que debió ser un grueso muro de mampostería irregular trabado con barro a juzgar por el cúmulo de piedras y la ausencia de restos de cal entre las mismas ${ }^{35}$. En la parte superior del despoblado pudo existir una torre circular, según puede verse en una foto aérea. Un poco más abajo de este punto, orientado al sur, hay restos de lo que parece ser una habitación con enlucido de yeso. La cava de nieve (¿siglos XVI-XVIII?) que se levanta junto al lugar debió construirse aprovechando las piedras existentes en el antiguo asentamiento, pero en los muros y bóveda de la misma no hay restos de fragmentos de piedras trabadas con mortero de cal. De esto puede deducirse que posiblemente los habitantes del despoblado no utilizaron este material en las construcciones que allí levantaron.

Cronología: Siglos X-XI a XIII.

\subsection{El Pic del Benicadell $(\boldsymbol{P})^{36}$}

Municipio: Gayanes (Alicante), Beniarrés (Alicante) y Beniatjar (Valencia)

Localización: Cartografía Militar de España, Mapa General, serie L, 1991, E. 1: 50.000, Alcoy 29-32 (821), punto 30SYJ252016. Mapa Topográfico Nacional de España, Muro de Alcoy 821-I (57-63), E. 1: 25.000, Instituto Geográfico Nacional, Madrid 1997 (1. ${ }^{\mathrm{a}} \mathrm{ed}$.), punto 72523016.

Altitud: 1.104 metros.

Distancias aproximadas en línea recta: al Alt del Benicadell, $650 \mathrm{~m}$ y al Guatleró, $950 \mathrm{~m}$.

Situación: Cresta rocosa de unos diez metros de anchura en la cima, apoyada sobre dos grandes lomas, protegida al norte y al sur por profundos precipicios, siendo los lados este y oeste pronunciadísimas pendientes. Es el punto desde el que se tiene un mayor dominio visual del entorno. Esta cresta se prolonga durante varios cente-

${ }^{35}$ R. Azuar, al describir El Castellar de Alcoy, asentamiento de similar cronología, dice: “... el yacimiento está defendido por su parte inferior y su frente superior por unas murallas de gruesos muros realizados en mampostería trabada con mortero de barro, estando sus laterales abrigados por sendos escarpes rocosos". Vid. Denia islámica, 134.

${ }^{36}$ No confundir con la Penya del Benicadell, situada al norte del Pic, a $847 \mathrm{~m}$ de altura. En dicho lugar no hay restos de cerámica ni de construcción alguna. 
nares de metros en pendiente hacia el este y se va estrechando hasta llegar en su extremo oriental a superar los 40 metros de altura.

Materiales: Se encuentran fragmentos de todas las series cerámicas halladas en el Alt (a excepción de la base de ataifor de pie anular con moldura y de tapadera, formas estas que no he podido localizar). Existen, además, cerámicas decoradas con técnica de cuerda seca y estampilladas bajo cubierta vidriada en verde así como cubiertas azul turquesa. Jarrita-o decoradas con rayas rojas o negras. Fragmentos de alcadafe ${ }^{37}$. Hay también cerámicas de épocas posteriores de dificil identificación cronológica y tipológica dada su fragmentación. Incluso pueden verse restos de cerámicas modernas.

Restos arquitectónicos: Nada ha quedado en pie ${ }^{38}$. En el pequeño collado que se forma entre la cresta y la primera loma se encuentra el pozo que ya fue descrito por Cavanilles a finales del siglo XVIII y según el cual en él se recogían las aguas llovidas y la nieve derretida. Sólo he podido ver un bloque suelto de tapial de alrededor de un metro cúbico de lo que debió ser el castillo y que desapareció a causa de un terremoto que dejó visibles rastros en toda la masa rocosa del Benicadell ${ }^{39}$. A pesar de esto, aún pueden verse fragmentos de mortero de cal y mampuestos irregulares, así como algún fragmento de ladrillo y teja diseminados por la pendiente situada al este. También, en la parte superior de la cresta, hay una brecha natural que pudo ser aprovechada como habitáculo a juzgar por unos pocos fragmentos de atanor, que creo posteriores al siglo XIII y que se encontraban en la superficie de dicho lugar.

Cronología: La presencia de las distintas tipologías cerámicas y técnicas decorativas arriba descritas parecen indicar que el lugar estuvo ocupado desde los siglos X-XI hasta después del siglo XIII.

\footnotetext{
37 Éste es el único de los tres yacimientos en los que he encontrado fragmentos de borde de alcadafe que pueden corresponder al Tipo A o C descritos por G. Roselló Bordoy. Vid. Ensayo de sistematización de la cerámica árabe en Mallorca, Palma de Mallorca, 1978, 60-62.

38 A pesar de las numerosas excursiones que he efectuado a este lugar no he conseguido localizar la torre de $4 \times 3 \mathrm{~m}$, que cita indirectamente J. Torró en "Fortificaciones...", 400 , nota 23. Lo único que se le parece son los restos de tres muros de medio metro de grosor que debieron pertenecer a algún tipo de refugio. Dichos restos están situados junto al pozo y creo que, por su construcción, no son anteriores al final del siglo XVIII.

${ }^{39}$ Vid. supra nota 28.
} 


\subsection{El Guatleró (G)}

Municipio: Beniarrés (Alicante)

Localización: Cartografia Militar de España, Mapa General, serie L, 1991, E. 1: 50.000, Alcoy 29-32 (821), punto 30SYJ261015. Mapa Topográfico Nacional de España, Muro de Alcoy 821-I (57-63), E. 1: 25.000, Instituto Geográfico Nacional, Madrid 1997 (1. ${ }^{\mathrm{a}}$ ed.), punto 72613015. En este mapa el lugar aparece con el nombre de «Cresta de Benicadell».

Altitud: 775 metros.

Distancias aproximadas en línea recta: al Alt del Benicadell, $1.550 \mathrm{~m}$.

Situación: Escarpe rocoso de muy pronunciadas pendientes que culmina en una estrecha y alargada pequeña meseta $\left(400 \mathrm{~m}^{2}\right.$, aprox.) defendida al norte por un enorme precipicio, a cuyo pie se encuentra encajonada entre este acantilado y la cuchilla que baja desde El Pic, una de las sendas por las que se accede a la cumbre del Benicadell.

Materiales: Idénticos materiales que los hallados en El Alt. Hay que añadir fragmentos de sílex y cerámicas hechas a mano con abundante desengrasante mineral, pertenecientes, sin duda, a un despoblado de la edad del Bronce.

Restos arquitectónicos: Acumulaciones de piedras en distintos lugares que pudieron formar parte de distintas construcciones situadas en el lugar. En la parte alta son aún visibles alineaciones de piedras (mampostería irregular sin restos de mortero de cal), bases de antiguos muros y numerosos fragmentos de teja. Más abajo de este yacimiento hay numerosos bancales de cultivo, hoy abandonados, cuyos muros de contención debieron construirse con piedras provenientes de la parte alta de este monte. No lejos de allí hay un antiguo horno para la fabricación de cal que también pudo abastecerse con piedras de este yacimiento, provocando su imparable erosión y su total destrucción.

Cronología: Siglos X-XI a XIII.

A modo de resumen podemos decir que estos tres yacimientos se asientan a gran altura, en escarpes rocosos y con impresionantes defensas naturales y por tanto, sin necesidad de importantes obras para convertirlos en lugares fácilmente defendibles ${ }^{40}$. Tienen en común al-

\footnotetext{
${ }^{40}$ Estos tres yacimientos, en su fase inicial de ocupación, podrían ser adscritos cronoló-
} gica y tipológicamente a la fase I establecida por Azuar en su extenso estudio sobre la zona 
gunas tipologías cerámicas, fundamentalmente fragmentos de tinaja con cordones aplicados, grandes asas y fragmentos de ataifor decorados en verde y manganeso ${ }^{41}$. La presencia de estas cerámicas parece indicar que los tres asentamientos surgen en una misma época que hay que situar tal vez a finales del siglo $\mathrm{X}$ o principios del siglo XI.

La ausencia, en El Guatleró y El Alt, de tipologías cerámicas y técnicas decorativas propias de la época de taifas parecen confirmar su abandono a mediados del siglo XI, pero es posible que volvieran a ser ocupados en el siglo XII, ya en época almohade (período éste del que sí hay cerámicas) y que antes del final de la primera mitad del siglo XIII fueran abandonados definitivamente. Este movimiento de ocupación y abandono de asentamientos no es exclusivo de esta sierra, sino que procesos similares han sido documentados en distintos puntos de la zona montañosa del norte de Alicante y en la cuenca del río Vinalopó ${ }^{42}$. El caso de El Pic es distinto, ya que en su superficie se encuentran las tipologías cerámicas suficientes para pensar que el lugar seguramente estuvo habitado de modo continuo, o que al menos no fue abandonado durante largos períodos de tiempo, entre los siglos X-XI y la segunda mitad del XIV como mínimo.

sur del País Valenciano centrado en la Denia islámica y su territorio. En dicho trabajo este investigador ofrece una serie de características generales de estos primeros asentamientos, como son el predominio de "poblados de considerables dimensiones, en yacimientos de una cierta altura y cuya defensa es la natural, sin preocuparse en desarrollar construcciones militares de envergadura [...] Los primeros asentamientos islámicos en la zona se producen a fines del siglo $\mathrm{X}$ y en concreto en el siglo XI, coincidiendo con la formación y desarrollo político de la Taifa de Denia, y corresponden a verdaderos "poblados fortificados", con unas importantes defensas naturales...". Vid. Azuar, R., Denia islámica, 340.

${ }^{41}$ Existen otros yacimientos en la zona con similares características. Vid. Cortell Pérez, E. y Torró Abad, J., "Dos yacimientos medievales en Serrella", Revista del Instituto de Estudios Alicantinos, 38 (1983), primer cuatrimestre, 101-116.

42 En un reciente trabajo y refiriéndose a la cuenca del río Vinalopó y a la zona montañosa del norte de Alicante, Azuar señala que algunos poblados de altura y ḥușūn documentados durante el califato se abandonan a finales del siglo $\mathrm{x}$ y principios del siglo XI. En algunos casos éstos no vuelven a habitarse; en otros, se pueblan de nuevo a mediados del siglo XII, según se desprende del análisis de la cerámica. El despoblamiento viene marcado por la ausencia de una producción típicamente taifal, como es la cuerda seca, parcial o total. Vid. Azuar, R., "Fortificaciones de Taifas en el Sharq al-Andalus", Castillos y territorio en al-Andalus, Granada, 1998, 118-121. 


\section{El Llibre dels feits: el asedio del Penacadell ${ }^{43}$}

El capítulo 370 de esta crónica nos dice que el rey Jaime I se halla en Valencia ${ }^{44}$ cuando le llega un mensaje informándole de que Penacadell está siendo asediado ${ }^{45}$. El rey considera que si el castillo cae en manos de al-Azraq podrían perderse una serie de importantes ciudades ${ }^{46}$. A la vista de estas noticias Jaime I reúne a los personajes más importantes de la ciudad y, con ellos, a gente de armas experta en acciones de guerra. El propio rey parece decidido a ir al frente de sus tropas para levantar el asedio, pero se le recomienda que abandone esa idea, ya que esta campaña podría no terminar bien. En este mismo capítulo se menciona también la derrota que han sufrido unos tres mil cristianos a manos de los musulmanes en la zona de Eslida y Veo, en la Serra d'Espadà (Castellón).

El texto en el que se relata la batalla para levantar el asedio del $\mathrm{Pe}$ nacadell ${ }^{47}$ está contenido en el capítulo siguiente (el 371) de esta crónica y a través de él creo que puede hacerse un seguimiento del desarrollo de dicho ataque. Al tiempo que ofrezco la traducción del mismo, divido el texto en párrafos que se corresponden, a mi juicio, con las posibles fases del mencionado combate y adjudico una letra a cada uno de los lugares implicados directamente en la batalla. Con ello pretendo hacer más comprensible lo contenido en este episodio, aplicando la hipótesis según la cual el castillo pudo estar situado en $E l$ Pic (P), mientras que los dos cerros desde los que se hostigaba el cas-

43 Sigo y traduzco el texto de la edición de F. Soldevilla, Crònica o Llibre dels Feits, Barcelona, 19882, 315. También utilizo para comparar los nombres mencionados la edición de J. Bruguera, II, Barcelona, 1991, 282. Con el fin de asegurar una correcta interpretación de los vocablos y expresiones arcaicas manejo la edición, introducción, transcripción y actualización de Ferrando, A. y Escartí, V. J., Llibre dels Fets de Jaume I, Catarroja-Barcelona, 1995, 225.

44 Vid. supra nota 4.

45 “... e venc un dia messatge a nós que combatien Penacadell, e que hi paraven algarrades, e combatien-los sovent e menut, a escut e a llança. E nós érem en València..." Crònica, ed. F. Soldevila, cap. 370, 314.

46 “... vengut nos era messatge que Penacadell combatien, e que hi voliem anar per tal que els en llevàsem: car si Penacadell se perdia, lo port de Cocentaina se perdria, que no gosaria hom anar a Cocentaina, ni a Alcoi, ni a les partides de Seixona, ni a Alacant per negun lloc e seria gran desconhort dels crestians", ibid.

47 En la ed. de J. Bruguera, II, cap. 370, 281, aparece como Penacadel y en la ed. de F. Soldevilla, cap. 370, p. 314, Penacadell. 
tillo serían El Alt del Benicadell (A) y El Guatleró (G) (Figs. 3, 4 y 5). Mi interpretación del pasaje es la siguiente:

FASE 1 (fig. 11): «Y, después de esto, allí fueron. Y los sarracenos tenían dos cerros, uno (A) acá de la peña (P), y el otro allá (G), así que los nuestros tuvieron que combatirlos con caballos armados y hombres de a pie».

FASE 2 (fig. 12): «Y les tomaron el cerro (A) que era de la parte de los nuestros. Y aquí murió Abetibassol ${ }^{48}$, que era el mejor sarraceno que Almaçarich ${ }^{49}$ tenía y el más poderoso, e incluso más valeroso que él».

FASE 3 (fig. 13): «Y, con la ayuda de Dios, los cristianos vieron ${ }^{50}$ que perdían también el cerro los de allá (G), y los sarracenos que estaban acá (A) vieron que Abenbaçol fue muerto, y se trasladaron al cerro de allá $(\mathbf{G})$ ».

FASE 4 (fig. 14): «Y los cristianos creyeron que no lo abandonarían, y no pusieron guardias al pie del cerro (G). Y todos los sarracenos salieron, y fueron a refugiarse a Alcalà, en tierra de al-Azraq. Y desde entonces los cristianos tomaron coraje, y fue bajando el poder de los sarracenos...».

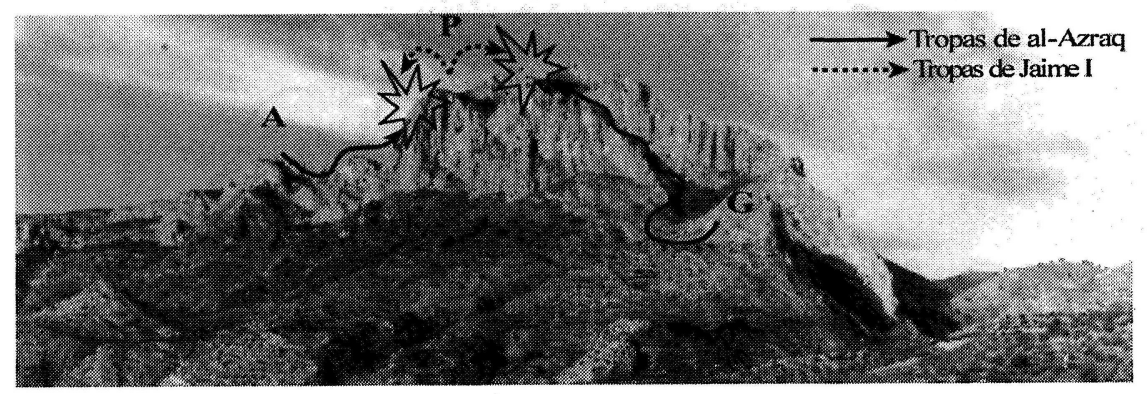

FIG. 11.-El extremo oriental de la sierra desde el sur. Ataque fase 1: El castillo (P), en manos de los hombres de Jaime I, es asediado y atacado por las tropas de al-Azraq desde dos cerros (A y G) situados a ambos lados de la peña en la que se encuentra el castillo.

${ }^{48}$ En edición de F. Soldevilla, cap. 371, p. 315, este nombre aparece con la forma Abetibassol y Abenbaçol. La ed. de J. Bruguera, cap. 371, p. 282, recoge las variantes Abenbazol y Abenbazel.

49 A. Ferrando y V. J. Escartí, Llibre, p. 225, consideran que se trata de al-Azraq. La misma interpretación hizo J. Ribera al traducir parcialmente este texto al castellano. Vid. "Un rey ignorado en la Contestania. El Cid en Benicadell", El Archivo, I (1886), ed. facsímil, Alicante, 1985, 97-102.

50 En ninguna de las ediciones que he utilizado de esta fuente se interpreta "veeren" con otro significado que no sea el de "ver" en sentido literal. 


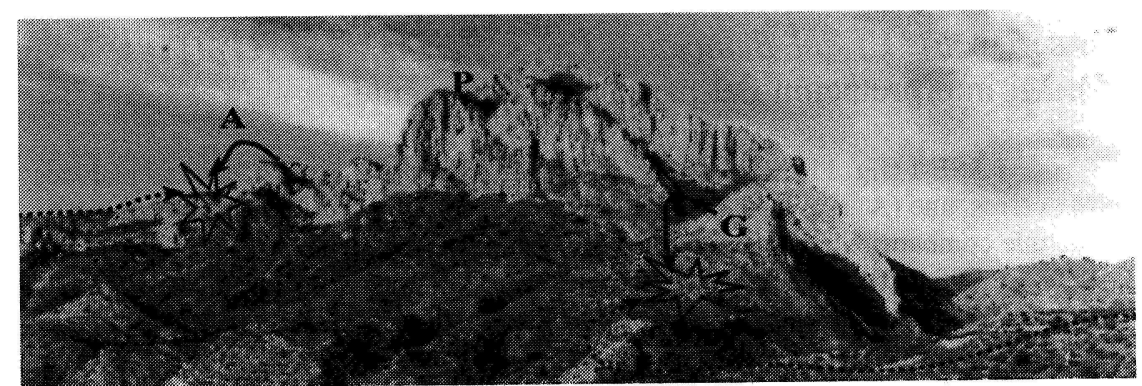

FIG. 12.-Ataque fase 2: Los refuerzos enviados por Jaime I atacan los dos cerros (A y G) desde los que al-Azraq está hostigando el castillo (P). Estos refuerzos consiguen tomar uno de los cerros (A).

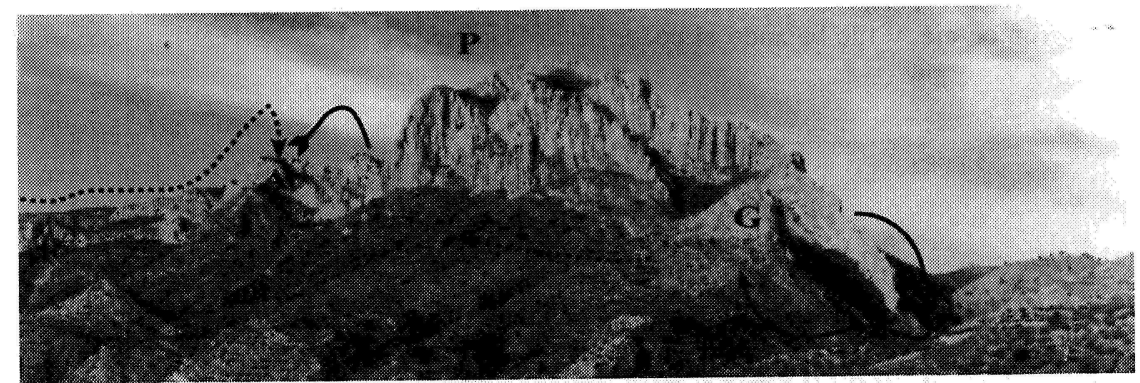

FIG. 13.-Ataque fase 3: Muerto Abenbaçol y perdido uno de los cerros (A), los hombres de al-Azraq se trasladan al otro cerro $(\mathrm{G})$.

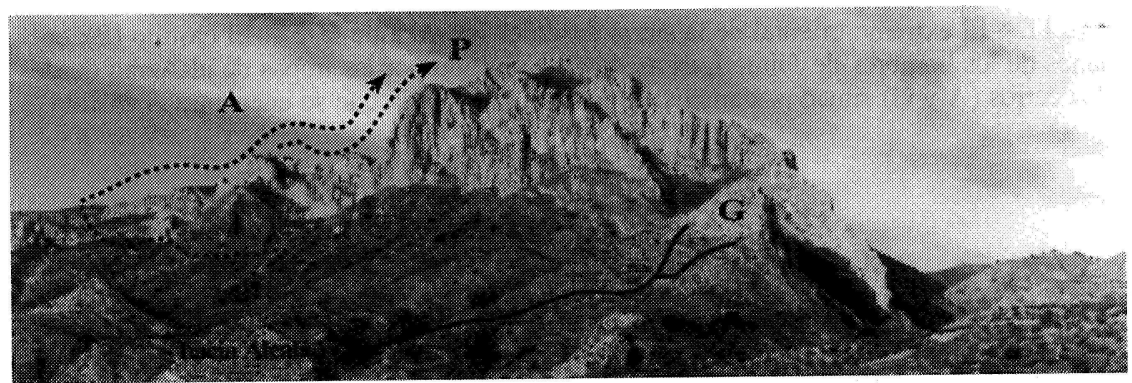

FIG. 14.-Ataque fase 4: Los hombres de al-Azraq aprovechan la ausencia de tropas enemigas al pie del cerro $(G)$ y se retiran hacia la zona segura de Alcalá. 
En relación a este pasaje se infiere que:

1. Los hombres de al-Azraq tienen en su poder dos cerros situados a ambos lados de la «peña».

2. A pesar de la peña, un cerro es visible desde el otro.

3. Se puede ir de un cerro al otro evitando la peña.

A partir de esto conjeturo que:

a) Estos dos cerros en los que se establece la tropa de al-Azraq debían ser dos posiciones con cierta altura respecto al inmediato entorno circundante con el fin de poder defenderse de un posible ataque por sorpresa de los soldados del castillo o incluso hacer frente, desde una posición ventajosa, a tropas llegadas en auxilio del castillo.

b) Los dos cerros no debían estar lejos del castillo para que los asaltantes pudieran controlar e incluso cerrar las sendas por las que llegar o salir de él. Pero a su vez debían estar lo suficientemente lejos para mantenerse fuera del alcance de las armas arrojadizas que pudieran tener los ocupantes del castillo.

c) Estos dos cerros debían ser lugares suficientemente espaciosos y seguros, por lo que a su defensa se refiere, para poder albergar a la tropa que asediaba y cercaba el castillo. Es obvio que la cantidad de hombres que compone el grupo de los atacantes ha de ser superior a la de los asediados.

d) El que un cerro fuera visible desde el otro facilitaría la coordinación a la hora de atacar el castillo, de llevar a cabo cualquier acción y sobre todo de estar informado de lo que pasaba en cada uno de ellos.

Visto lo que antecede creo que tanto El Alt como El Guatleró reúnen todas las condiciones para ser los dos cerros mencionados en la Crònica de Jaime I. Prueba de ello son los asentamientos levantados allí siglos antes y que en el momento de este asedio no eran ya sino ruinas que bien pudieron servir a los hombres de al-Azraq para resguardarse y defenderse mejor.

Este texto, al tiempo que relata con detalle la forma en que se produjo el enfrentamiento, plantea algunas preguntas desde el punto de vista táctico, pero una de ellas es fundamental, ya que en su respuesta se encuentra todo el desarrollo de este hecho de armas y puede servir para ubicar el lugar en el que creo que se asentaba el castillo: ¿por qué al-Azraq decide atacar desde dos cerros? Creo que la solución puede estar en la propia configuración del terreno y, sobre todo, en los caminos de acceso para llegar hasta El Pic del Benicadell. La posesión de estos dos cerros que identifico con el Alt del Benicadell y El Guatleró, tal y como acabo de señalar, suponía de hecho poder bloquear los caminos por los que se accedía y aún se accede al Pic, ya que es del 
todo imposible llegar a este lugar sin pasar por el pie de estos dos promontorios.

Dada la configuración del terreno y lo angosto del Pic es posible que el castillo tuviera dos puertas, lo cual, a primera vista, podría suponer un cierto debilitamiento para su defensa, pero ahorraba sin duda mucho tiempo a la hora de salir o entrar en él, evitando a sus ocupantes tener que dar grandes rodeos en caso de que tuvieran que salir o entrar en él, cualquiera que fuese el motivo. Una de las puertas estaría orientada hacia el este y la otra hacia el oeste. Tal vez a este hecho, es decir, a la existencia de más de una puerta y a los caminos de acceso, se refiere el Poema de Mio Cid, Cantar Segundo:

«ganaron Peña Cadiella, las exidas e las entradas.» 1163

Ian Michael, en su edición del Poema ${ }^{51}$, señala que la expresión «... las exidas e las entradas» en la terminología legal significa «el acceso (al castillo)» o mejor dicho, en este caso, «los accesos»; sin embargo, Menéndez Pidal interpretó aquí «las exidas e las entradas» de Valencia ${ }^{52}$.

\section{Conclusión}

A favor de la posible ubicación del castillo en El Pic están las cerámicas halladas pertenecientes al período comprendido entre finales del siglo X y el siglo XIV, la presencia de un pozo, el excepcional dominio visual del lugar y el testimonio dado por la Crònica de Jaime I.

Esta fortaleza en poder del Cid y de Alfonso I fue un punto de apoyo para incursiones militares, una especie de pequeño Aledo, y una fuente de información de primera mano para quien lo tenía en su poder. A todo esto debemos añadir la presión psicológica que desde él se podía ejercer sobre los alrededores, puesto que estaba enclavado en un lugar visible a decenas de kilómetros. Por la situación político-militar del oriente de al-Andalus, durante el resto del siglo XII y primera

51 Poema de Mio Cid, p. 159, en nota. Esta expresión se repite en el verso 1572.

52 Menéndez Pidal, R., La España del Cid, I, 435. Por su parte, C. Smith, en su edición del Poema de Mio Cid, Madrid, 19817, 289, señala que esta expresión "... es una frase legal muy antigua que significa "todos los términos de un terreno". Bajo el imperio franco cum exsitu et regresso constituía ya una fórmula, y se la encuentra en España por lo menos desde el año 870". 
mitad del XIII, la fortaleza perteneció primero a los almorávides, según se deduce del testimonio de al-Idrīsī, quien lo menciona como hișn Binnah Qațāl, y luego pasó a los almohades. Con la llegada de las tropas catalano-aragonesas, a mediados del siglo XIII, se convirtió temporalmente en un castillo de frontera. A partir de la segunda mitad de ese siglo y hasta después de mediados del siglo XIV fue sede de un alcaide y cabeza de un distrito castral del que dependían otras fortificaciones.

\title{
RESUMEN
}

En este trabajo se intenta localizar el lugar en el que pudo asentarse el castillo de Penna Cadiella mencionado en el Poema de Mio Cid. Para ello, se retoma la hipótesis que en su día planteara P. Guichard sobre su ubicación en la cima de la Sierra de Benicadell (Valencia-Alicante) y se aportan nuevos datos documentales y arqueológicos. Asimismo, se analiza el capítulo 371 de la Crónica de Jaime I en el cual se relata la batalla que, por su posesión, libraron las tropas del rey aragonés contra al-Azraq a mediados del siglo XIII.

\begin{abstract}
In this article we try to locate the place where the castle of Penna Cadiella, mentioned in the Poem of Mio Cid could had been built. To this we reintroduce the hypothesis expressed in its time by P. Guichard regarding the castle's location on top of the Benicadell range of mountains (Valencia-Alicante) and we provide new documentary and archaeological data. Likewise, we analyse the $371^{\text {st }}$ chapter of Jaime I's Crónica in which the battle fought for the possession of the above-mentioned castle by the troops of the Aragonese king against al-Azraq in the thirteenth century is narrated.
\end{abstract}

